\title{
An intradermal skin test for determination of immunity to varicella
}

\author{
E Somekh, Y Bujanover, G Tal, I Dalal, A Tanay, D Lehman
}

\begin{abstract}
Aims-To evaluate the usefulness of a diluted, inactivated solution of attenuated varicella vaccine in predicting susceptibility to varicella and its correlation with specific antibody titre to varicella.

Methods-In a prospective blinded study, 63 healthy subjects (aged 2-43 years) were studied. Skin test solution was prepared from vials of OKA strain virus which was inactivated by exposure of the vials to room temperature for 10 days; solution was diluted at $1 / 50$ with normal saline and kept at $4^{\circ} \mathrm{C}$ until used for skin testing. The material was injected intradermally. Serum samples were drawn prior to skin testing and kept at $-70^{\circ} \mathrm{C}$ until analysis for antibody assay by the indirect fluorescent antibody (IFA) method.
\end{abstract}

Results-Forty three patients were IFA antibody positive; 41 of them reacted to the skin test. One of the 20 IFA negative patients reacted to the skin test. Sixteen patients had two serological tests performed, one month apart. Four out of these 16 patients tested negative with the skin test. All four had negative serology on both samples. Six of the 12 IFA positive patients showed a boost in the antibody titre one month after application of the skin test. The specificity and sensitivity of the skin test compared to the IFA assay were both $95 \%$, and the positive and negative predictive values were $97 \%$ and $90 \%$ respectively.

Conclusions-Results suggest that a varicella skin test prepared using this simple and relatively cheap method is a safe, sensitive, and specific tool by which to assess immunity to varicella.

(Arch Dis Child 2001;85:484-486)

Keywords: skin test; varicella; immunity; serology

In 1977, Kamiya et al reported the use of an intradermal varicella skin test in healthy children. ${ }^{1}$ Since then, a number of investigators have evaluated its use as a diagnostic tool, and as a measure of the immune response to varicella zoster virus (VZV) in both healthy and immunocompromised hosts. ${ }^{2-7}$

Several studies have shown that the intradermal skin test has been an effective means by which to evaluate immunity to varicella. The skin test generally used has been prepared from supernatant of VZV (OKA strain) infected MRC-5 cells, in a process which included centrifugation and heating. Another method was the usage of purified VZV glycoproteins as $\mathrm{gB}$, gE:gI, and gH:gL. ${ }^{3}$

These preparations were proved to be safe and reliable; however, they are not widely available and are mainly used in research institutes. Thus, most physicians in Israel as well as in many other countries have used the antibody response as the single laboratory test to determine the susceptibility to varicella when the history is questionable.

In order to simplify the procedure of skin testing for varicella, we prepared an inactivated preparation of the varicella vaccine.

In this study, we evaluated the usefulness of a diluted, inactivated solution of attenuated varicella vaccine in predicting susceptibility to varicella and its correlation with specific antibody titre to varicella.

\section{Methods}

Sixty three healthy patients (26 females, 37 males; aged 2-42 years), constituted the study population (mean age 4.6 (SD 9.2) years). Pregnant women were excluded from the study. Patients or their caregivers recorded the history of varicella and signed a consent form to participate in the study. The study was approved by The Ethics Committee of the Edith Wolfson Medical Center.

All skin tests used the Mantoux technique with tuberculin syringes and 25 gauge needles. Material was applied in the usual manner by injecting $0.1 \mathrm{ml}$ intradermally into the volar surface of the forearm. A sterile solution of normal saline, injected in the same manner at a different site, was used as control skin test. Tests were considered positive when the diameter of erythema and induration was $5 \mathrm{~mm}$ or larger, and the control site was less than $5 \mathrm{~mm}$, at 48 hours, using the ballpoint pen technique. ${ }^{8}$ Skin tests was evaluated on a blinded basis (the evaluator did not know the immune status of the patient when reading the test).

Skin test solution was prepared from vials of OKA strain varicella vaccine (Pasteur Merieux, Lyon, France) containing, according to the manufacturer's information, at least 2000 plaque forming units $/ 0.5 \mathrm{ml}$ vial. Vials were left at room temperature for 10 days. Exposure for such a time period has been shown to be sufficient to destroy the labile viable virus. ${ }^{1}$ Samples from the vial were cultured in MRC-5 cells. When no virus was grown in the tissue culture, the solution was diluted at $1 / 50$ using $4.5 \mathrm{ml}$ vials with $20 \mathrm{~mm}$ closure, containing $0.9 \%$ sterile saline and $0.4 \%$ phenol as preservative (Center Laboratories, Port Washington, New York). The vials were kept at $4^{\circ} \mathrm{C}$ for up to one month until used for skin testing.
Accepted 10 September 2001 
ANTIBODY ASSAY

A serum sample was drawn prior to skin testing and was kept at $-70^{\circ} \mathrm{C}$ until the antibody assay was performed. A second serum sample was taken from 16 patients one month after skin testing. Antibodies to VZV were measured by the indirect fluorescent antibody (IFA) method (Gull Laboratories Inc., Salt Lake City, Utah), using VZV (Ellen strain) infected human fibroblast cells and uninfected cells as antigen and control, respectively. ${ }^{9}$

\section{Results}

SAFETY

Skin test application was uneventful; except for local erythema and induration, there were no other local or systemic manifestations. No patient with negative history for varicella developed chickenpox within two months from skin testing.

EFFICACY

Forty three patients were IFA antibody positive, of which 41 reacted to skin test. One of the 20 IFA negative patients (aged 10 years) reacted to the skin test.

Thirty seven patients had a positive history for varicella. All had a significant antibody titre to VZV as tested in our assay, while six of the 26 patients with negative history for chickenpox had significant antibody titre to VZV.

Sixteen patients had two serological samples obtained one month apart and analysed simultaneously. Four of these 16 patients tested negative with the skin test. All four had negative serology on both samples. Six of the 12 IFA positive patients had a booster response (fourfold or greater rise in titre of antibody) one month after application of the skin test.

\section{Discussion}

The cell mediated immune response plays a major part in protection from VZV infection. ${ }^{10}$ Since skin test reactivity is an indirect assessment of cellular immune response, varicella skin testing may be an efficient and reliable tool in determination of susceptibility to $\mathrm{VZV}$, as shown in studies using fluid from VZV infected cells. ${ }^{12}$ However, in spite of the fact that skin testing does not require diagnostic laboratory facilities and staff, most physicians throughout the world still prefer the more sophisticated antibody assay as the tool of choice in the assessment of immunity to varicella.

In this study we evaluated a simple method for preparing varicella skin test and examined the skin test safety and efficacy. The skin test used by us was well tolerated and side effects were minimal. Skin testing did not induce seroconversion in the four seronegative patients as in previous reports, ${ }^{26}$ suggesting that skin tests do not obscure interpretation of serology following exposures. Shiraki et al showed, in a guinea pig model, that only large amounts of skin test antigen given repeatedly could provoke a primary immune response. ${ }^{11}$ In contrast, six of 12 IFA positive patients had booster responses following application of skin test antigen, as previously reported by LaRussa and colleagues. ${ }^{2}$ These immunological responses to the skin test show some similarity to tuberculin skin testing. ${ }^{12}$

Skin tests were read 48 hours after application based on previous histological findings, showing that this was the optimal time to interpret the skin test. ${ }^{2}$ The skin tests results generally correlated well with those obtained with the IFA assay; sensitivity and specificity of the skin test compared to the IFA assay were $95 \%$ each. The positive predictive value was $97 \%$, and the negative predictive value $90 \%$.

The negative predictive value of negative history of varicella infection in the past in our sample was relatively high compared to previous surveys $(77 \%)$. This relatively high figure is probably a result of the fact that many of the patients in our study were children, in whom a past history of varicella is more reliable than in adults. ${ }^{13}$

In two of our patients the skin test was negative in spite of positive serology. In one of these patients the serology was weakly positive. The false negative results may be caused by an inadequate injection technique or low skin reactivity. One patient reacted to the skin test in spite of positive serology. It is possible that the patient reacted to non-VZV components in the solution (for example, the stabiliser or the neomycin). It is also possible that in this case serology was actually false negative, which may be seen in the IFA assay. ${ }^{9}$ However, in light of the extensive use of the IFA assay for diagnosis of varicella, the discrepancy between the serological and the skin test results should be counted as false positive skin test results. False positive and false negative reactions were not related to age of the patients.

We believe that skin testing may add another tool for assessing immunity to varicella in circumstances where antibody testing is not readily available or when the serological results are equivocal. However, although serology can be performed within a few hours, the results may not be available to the physician, even after the 48 hours from presentation at the physician's clinic that a skin test takes to perform.

Skin testing may be also useful for screening purposes, for example before vaccination when the varicella status of a person is unknown.

Although skin testing may be considered a relatively invasive procedure, in our group of patients the test was not accompanied by significant inconvenience or pain, and was well tolerated.

The safety of the skin testing procedure was assessed by several criteria. Firstly, safety was assured by the lack of viable attenuated virus in the solution. Secondly, no patient with a negative history for varicella developed varicella or varicella like illness within two months of skin testing. Finally, all four seronegative patients who had serology testing one month after the test, did not serocovert following the test. Another precaution was not to administer the test to immunocompromised patients or to any person in whom a live varicella vaccination was otherwise contraindicated.

It should be emphasised that if this skin test were to be used in practice, testing should be 
performed only in clinics experienced with intradermal testing (as with tuberculin testing), and capable of obtaining, using, and manipulating the vaccine. Furthermore, such use falls outside the indications and methods of administration for which the vaccine is licensed.

In future, it might be informative to study the use of this skin test in immunocompromised patients and pregnant women, groups in which it might be useful. Previous reports have suggested that varicella skin test reactivity may be impaired in the immunosuppressed host. ${ }^{14}{ }^{15}$ However, since cell mediated immunity is crucial in the host defence during varicella infection, skin test reactivity may be a more accurate measurement of immunity to this infection than antibody titre.

Another practical use of this skin test may be the addition of another antigen to test delayed type hypersensitivity in patients with positive past history of varicella infection, as part of investigations for immunodeficiency. We believe that if these results are reproduced in larger studies, this test may prove to be an accessible clinical tool when facing a varicella dilemma.

Part of this work was presented at the 37th Annual Meeting of the Infectious Diseases Society of America, 18-21 November, Philadelphia, Pennsylvania, 1999 (Abstract no. 717).

1 Kamiya H, Ihara T, Hattori A, et al. Diagnostic skin test reactions with varicella virus antigen and clinical application of the test. F Infect Dis 1977;136:784-8.
2 LaRussa P, Steinberg SP, Seeman MD, Gershon AA. Determination of immunity to varicella-zoster virus by means of an intradermal skin test. F Infect Dis 1985;152:869-75.

3 Sato H, Kageyama S, Imakita M, et al. Immune response to varicella-zoster virus glycoproteins in guinea pigs infected with Oka varicella vaccine. Vaccine 1998;16:1263-9.

4 Ihara $\mathrm{T}$, Kato $\mathrm{T}$, Torigoe $\mathrm{S}$, et al. Antibody response determined with antibody-dependent cell-mediated cytotoxicity (ADCC), neutralizing antibody, and varicella skin test in children with natural varicella and after varicella immunization. Acta Paediatr fpn 1991;33:43-9.

5 Baba K, Shiraki K, Kanesaki T, et al. Specificity of skin test with varicella-zoster virus antigen in varicella-zoster and herpes simplex virus infections. F Clin Microbiol 1987;25: 2193-6.

6 Berger R, Luescher D, Just M, et al. Delayed hypersensitivity skin test to detect susceptibility to varicella and zoster. Postgrad Med f 1985;61(suppl 4):137-41.

7 Steele RW, Coleman MA, Fiser M, Bradsher RW. Varicella zoster in hospital personnel: skin test reactivity to monitor susceptibility. Pediatrics 1982;70:604-8.

8 Sokal JE. Editorial. Measurement of delayed skin-test responses. N Engl f Med 1975;293:501-2.

9 Williams V, Gershon A, Brunell PA. Serologic response to varicella-zoster membrane antigen measured by indirect immunofluorescence. 7 Infect Dis 1974;130:669-72.

10 Bogger-Goren S, Bernstein JM, Gershon AA, Ogra PL. Mucosal cell-mediated immunity to varicella zoster virus: role in protection against disease. $f$ Pediatr 1984;105: role in

11 Shiraki K, Yamanishi K, Takahashi M. Biologic and immunologic characterization of the soluble skin-test antigen of varicella-zoster virus. $\mathcal{F}$ Infect Dis 1984;149:501-4.

12 Haas DW. Mycobacterium tuberculosis. In: Mandell GL, Bennett JE, Dolin R, eds. Principles and practice of infectious diseases. Philadelphia: Churchill Livingstone, 2000:2576607.

13 Kositanont U, Wasi C, Oonsombat $\mathrm{P}$, et al. Susceptibility to varicella-zoster virus in Thai children and young adults. Southeast Asian f Trop Med Public Health 1985;16:414-20.

14 Tanaka Y, Harino S, Danjo S, et al. Skin test with varicellazoster virus antigen for ophthalmic herpes zoster. $\mathrm{Am} \mathcal{F}$ Ophthalmol 1984;98:7-10.

15 Ishikawa O, Abe M, Miyachi Y. Herpes zoster in Japanese patients with systemic lupus erythematosus. Clin Exp Dermatol 1999;24:327-8.

\section{7th European Forum on Quality Improvement in Health Care}

\section{1-23 March 2002 \\ Edinburgh, Scotland}

We are delighted to announce this forthcoming conference in Edinburgh. Delegate enquiries are welcome.

The themes of the Forum are:

- Leadership, culture change, and change management

- Achieving radical improvement by redesigning care

- Health policy for lasting improvement in health care systems

- Patient safety

- Measurement for improvement, learning, and accountability

- Partnership with patients

- Professional quality: the foundation for improvement

- Continuous improvement in education and training

- People and improvement.

Presented to you by the BMJ Publishing Group (London, UK) and Institute for Healthcare Improvement (Boston, USA). For more information contact: quality@bma.org.uk or look at the website www.quality.bmjpg.com. Tel: +44 (0)20 7383 6409; fax: +44 (0)20 73736869 . 